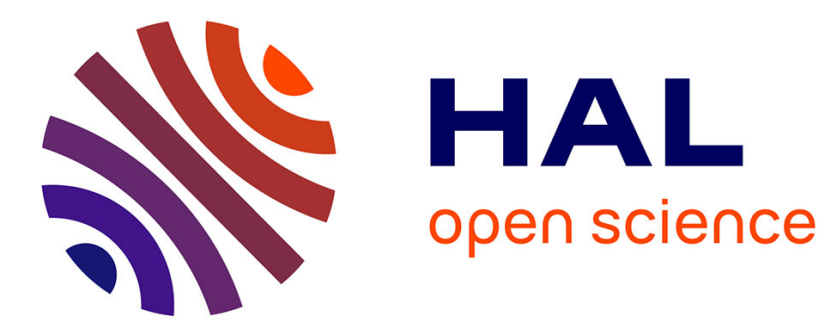

\title{
Photophysics of Calcium Green 1 in vitro and in live cells
}

\author{
Laetitia Schoutteten, Patrick Denjean, Jean Faure, Robert Bernard Pansu
}

\section{To cite this version:}

Laetitia Schoutteten, Patrick Denjean, Jean Faure, Robert Bernard Pansu. Photophysics of Calcium Green 1 in vitro and in live cells. Physical Chemistry Chemical Physics, 1999, 1, pp.2463-2469. hal-00842088

\section{HAL Id: hal-00842088 \\ https://hal.science/hal-00842088}

Submitted on 7 Jul 2013

HAL is a multi-disciplinary open access archive for the deposit and dissemination of scientific research documents, whether they are published or not. The documents may come from teaching and research institutions in France or abroad, or from public or private research centers.
L'archive ouverte pluridisciplinaire HAL, est destinée au dépôt et à la diffusion de documents scientifiques de niveau recherche, publiés ou non, émanant des établissements d'enseignement et de recherche français ou étrangers, des laboratoires publics ou privés. 


\author{
Laetitia Schoutteten, Patrick Denjean, Jean Faure and Robert B. Pansu*
}

PPSM, Ecole Normale Supérieure, 94235 Cachan Cedex, France. E-mail:pansu@ppsm.ens-cachan.fr

Received 21st January 1999, Accepted 19th March 1999

The absolute measurement of calcium activity in cells is hindered by the presence of different forms of the probe (adsorbed, protonated). Time-resolved fluorescence spectroscopy can be a sensitive technique to separate contaminating forms of the probe. The fluorescent probe Calcium Green 1 was characterised, in vitro, in terms of calcium and also $\mathrm{pH}$ dependence, albumin adsorption, extent of hydrolysis, viscosity and medium polarity. A 1:1 stoichiometry was obtained for the calcium complexation with a $K_{\mathrm{d}}$ value that agrees with reported values. A $\mathrm{p} K_{\mathrm{a}}$ of the BAPTA moiety was measured as 6.7. The fluorescence lifetimes are slightly dependent on polarity but not on viscosity. It was observed that most of the interfering forms of the probe share the common lifetimes of 0.5 and $3.5 \mathrm{~ns}$. An alternative mechanism for Calcium Green 1 sensing is proposed based on a ground state conformational equilibrium affecting the photoinduced electron transfer.

\section{Introduction}

Fluorescent indicators for the determination of local ionic activities are now widely used, especially in cell biology. Until recently, the use of time-resolved single photon counting in biology was limited by the expense of pulsed lasers. The development of two-photon microscopy ${ }^{1}$ that requires a pulsed laser and the appearance of cheaper pulsed diode lasers has opened up the wider use of sensing based on time-resolved measurements. The purpose of this study was to investigate opportunities offered by time-resolved measurements in microfluorimetric studies. ${ }^{2}$ The first advantage associated with time measurement inside a microscope is that many optics constraints are bypassed. Compared with microspectrofluorimetric probes, whose spectral changes are used to monitor ionic activity, time-resolved probes do not rely on achromaticity of the optics and do not demand a perfect confocal alignment of the measurement ports associated with each wavelength. The second advantage, which is offered by the fluorescence lifetime, is its dependence on local environment. As an example, fluorescent molecules using photoinduced electron transfer (PET) ${ }^{3}$ as a probe mechanism have fluorescence yields that depend on the nature of the complexed ion, $\mathrm{H}^{+}, \mathrm{Na}^{+}$or $\mathrm{K}^{+}{ }^{4}$ This sensitivity of the fluorescence lifetime can be a way to perform absolute activity measurements in cells. ${ }^{5,6}$ Indeed, most intracellular measurements are hindered by the presence of other fluorescent forms of the probe such as the membrane-permeant precursors or protein adsorbed forms of the probe. Local viscosity ${ }^{7}$ and polarity effects and protein adsorption have also been reported to modify probe response. We chose Calcium Green 1, a calcium probe. Calcium Green is composed of a BAPTA chelating group, that provides sensitivity and selectivity for calcium, ${ }^{8}$ and dichlorofluorescein, whose fluorescence depends on the presence of calcium ion inside the molecule through a PET. ${ }^{9}$ The PET mechanism is not necessarily sensitive to the electronegativity of the ion ${ }^{10}$ but can be sensitive to the conformation of the probe. ${ }^{11} \mathrm{We}$ show that Calcium Green 1 is not sensitive to viscosity. Its sensitivity to local dielectric properties can be neglected. The slight change of the quenching rate with polarity is in agreement with a charge transfer mechanism. Calcium Green 1 has a three orders of magnitude sensi- tivity to $\mathrm{Ca}^{2+}$, from 0.3 to $200 \mathrm{nmol} \mathrm{L}-1$, with a $K_{\mathrm{d}}$ of 70 $\mathrm{nmol} \mathrm{L}{ }^{-1}$. Its sensitivity to $\mathrm{pH}$ cannot be neglected. Calcium Green 1 adsorbs on albumin. Lifetime measurement also offers an opportunity to measure rotational relaxation of the probe. ${ }^{12}$ We show that the adsorption of Calcium Green 1 on proteins in the cell can be quantified from in situ anisotropy measurements. The influence of adsorption on the fluorescence decay, the similarity between protonation and calcium complexation on the fluorescence decay and the effect of polarity on fluorescence decay show that Calcium Green 1 does not probe calcium by a through bound electron transfer modulated by the electronegativity of the ion, but by a ground state change in the conformational equilibrium induced by calcium complexation, protonation or adsorption, which also affects the photoinduced electron transfer.

\section{Experimental}

\section{Set-up}

The light source is a Tsunami 3950B titanium-doped sapphire laser from Spectra Physics (Les Ulis, France) operating at 900 $\mathrm{nm}$. The light frequency is doubled to $450 \mathrm{~nm}$ by a BBO crystal. The light pulses are $1 \mathrm{ps}$ in length. The pulse energy at the entrance of the microscope is $4 \mathrm{pJ}$. The microscope is inverted with a $\times 40$ objective (Nikon, Diaphot-TMD). The epiluminescence set-up is removed and the parallel beam of the laser shines directly on the dichroic mirror. In this way, the excitation beam is focused on the sample. The fluorescence light is collected behind the dichroic mirror with an optical fibre $50 \mu \mathrm{m}$ in diameter. This fibre acts as the aperture of a confocal microscope. ${ }^{13}$ The photons are detected using a multi-channel plate photomultiplier (R3809U, Hamamatsu, Massy, France). A constant fraction discriminator (Institut de Physique Nucléaire d'Orsay, France) is positioned directly behind the photomultiplier. We use a standard photon timing electronic that constructs the fluorescence decay curve as a histogram of single photon arrival delay within a few minutes. The performances of this set-up have been described elsewhere. $^{14}$ Independently, a single channel analyser (Schlumberger) placed behind the time to amplitude converter (TC864 Tennelec, Aries, Chatenay Malabry, France) is used to 
count photons arriving later than $2.47 \mathrm{~ns}$ after the laser pulse. The screen displays three kinds of data: the total photon count, the late photon count every $10 \mathrm{~ms}$ and the fluorescence decay curve. For ex vivo studies, the acquisition is programmed for 2 min for each cell. For cells studies, the excitation wavelength is set to $495 \mathrm{~nm}$, so that the autofluorescence is drastically reduced compared with $450 \mathrm{~nm}$ excitation. Fluorescence is collected behind a $520 \mathrm{~nm}$ barrier filter.

\section{Reagents}

All reagents for cell culture were provided by Sigma Biosciences and were of the best purity grade, sterile-filtered and endotoxin tested.

Calcium Green TM-1, AM and the calcium calibration buffer kit were provided by Molecular Probes Europe (Leiden, The Netherlands).

\section{Cell culture}

The RINm5F cell line is a subclone of the original rat islet cell tumour RIN-r obtained following 1000 rad of total body Xirradiation to an inbred albino NEDH rat. ${ }^{15}$ RIN cells are grown in RPMI 40 medium supplemented with $10 \%$ foetal calf serum, $2 \mathrm{~mm}$ glutamine and antibiotics $\left(100 \mathrm{IU} \mathrm{mL} \mathrm{mL}^{-1}\right.$ penicillin $+50 \mu \mathrm{g} \mathrm{mL}^{-1}$ streptomycin) in a humidified $5 \%$ $\mathrm{CO}_{2}-95 \%$ air incubator at $37^{\circ} \mathrm{C}$. Two days before each experiment, cells are harvested with trypsin-EDTA $(0.05 \%-$ $0.2 \%$ ) and plated into glass chamber slides adapted to inverted microscopy (Nunc Lab-Tek glass cover-slip slides, Life Technologies, Pontoise, France) at a concentration of $5 \times 10^{5}$ cells per minichamber.

\section{Buffers}

At physiological $\mathrm{pH}$, Calcium Green 1 probes calcium through the following equilibrium:

$$
\mathrm{CaG}^{4-} \stackrel{K_{\mathrm{d}}}{\rightleftharpoons} \mathrm{Ca}^{2+}+\mathrm{G}^{6-}
$$

where $\mathrm{CaG}^{4-}$ the form of Calcium Green 1 complexed with calcium, $\mathrm{Ca}^{2+}$ is the calcium ion, $\mathrm{G}^{6-}$ is the free form of Calcium Green 1 and $K_{\mathrm{d}}$ is the dissociation constant of Calcium Green 1 for calcium.

Both the stoichiometry and the value of the affinity constant have to be checked. For this, we recorded the fluorescence decay profiles as a function of calcium activity. A calcium activity as low as $10^{-9} \mathrm{M}$ cannot be obtained by a simple weigh and dilution procedure, simply because the calcium that is released from clean glassware is above that level. We used the buffer proposed by Tsien, ${ }^{8}$ available from Molecular Probes.

EGTA fixes the calcium activity through the equilibrium

$$
\begin{gathered}
\mathrm{EGTAH}_{2}^{2-}+\mathrm{Ca}^{2+} \rightleftharpoons 2 \mathrm{H}^{+}+\mathrm{CaEGTA}^{2-} \\
K_{\mathrm{d}}=\frac{K_{\mathrm{d}}^{\prime}}{\left(\mathrm{H}^{+}\right)^{2}}
\end{gathered}
$$

where EGTAH $^{2-}$ is the free form of EGTA and CaEGTA ${ }^{2-}$ is the complexed form of EGTA with calcium. $K_{\mathrm{d}}^{\prime}=150 \mathrm{nmol}$ $\mathrm{L}^{-1}$ at $\mathrm{pH} 7.20$ and a ionic strength of $0.1 \mathrm{~mol} \mathrm{~L}^{-1}{ }^{8}$

Stock standard solutions $\mathrm{EGTAH}_{2}^{2-}$ and $\mathrm{CaEGTA}^{2-}$ were diluted to $5 \mathrm{mmol} \mathrm{L}^{-1}$ in a $\mathrm{pH}$ buffer solution containing the fluorescent probe, so that the final concentration of Calcium Green 1 remained constant on mixing the two solutions. The buffer was prepared from TRIS to a $\mathrm{pH}$ of 7.20. The ionic strength was fixed at $0.1 \mathrm{~mol} \mathrm{~L}^{-1}$ by the TRIS. At a total concentration of $5 \mathrm{mmol} \mathrm{L^{-1 }}$ in buffer, the change in $\mathrm{EGTAH}_{2}^{2-}$ and $\mathrm{CaEGTA}^{2-}$ induced by calcium glass release can be neglected compared with the total calcium concentra- tion. Hence the calcium activity remains fixed in a region near the $K_{\mathrm{d}}^{\prime}$ value.

EGTA was used also to study the $\mathrm{p} K_{\mathrm{a}}$ of the calcium free form of Calcium Green. The $\mathrm{pH}$ effect on Calcium Green in the calcium free solution cannot be due to a release of calcium by the buffer EGTA; indeed, the calcium free solution was obtained by the use of $5 \mathrm{mmol} \mathrm{L}^{-1}$ EGTA as a chelator of residual calcium ion. The calcium due to the release from the cuvette in Nanopure water was less than $5 \times 10^{-6} \mathrm{~mol} \mathrm{~L}^{-1}$. Upon acidification, the $\mathrm{p} K_{\mathrm{d}}{ }^{\prime}$ of the probe increases from 1.75 nmol $\mathrm{L}^{-1}$ to $3.7 \mu \mathrm{mol} \mathrm{L} \mathrm{L}^{-1}$ at $\mathrm{pH}$ 6.5. Hence the calcium activity remained between $1.75 \mathrm{pmol} \mathrm{L}^{-1}$ and $3.7 \mathrm{nmol} \mathrm{L}^{-1}$, which can be neglected.

\section{Results}

\section{Calcium calibration curve}

The fluorescence decays were recorded by adding successive aliquots of $\mathrm{CaEGTA}^{2-}$ to the $\mathrm{EGTAH}_{2}^{2-}$ solution and the reverse. It was checked that the zero delay intensity of the two extreme solutions of Calcium Green 1 are equal [Fig. 1(a)]. As predicted, the decay curves become longer as the calcium concentration increases.

The family of decays was submitted to a chemometric analysis. ${ }^{16,17}$ The first two main components describe $98 \%$ of the signal for an estimated error of $0.1 \%$. The weighted residuals are shown in Fig. 1(b). The family of curves exhibits a random change of sign, with a random pattern along both the time and calcium concentration axes.

The decays obtained for the minimum and maximum activity of calcium were used to construct reference decay profiles for the calcium bound and calcium free forms of Calcium Green 1. They can be expressed as a function of the two main components. As the two main components were averaged over
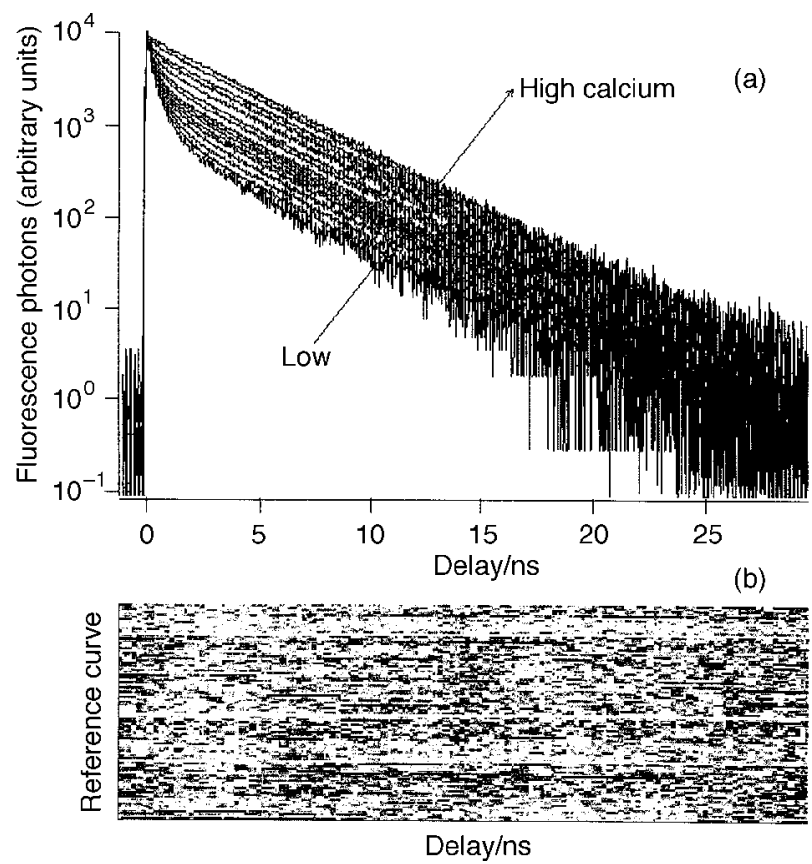

Fig. 1 (a) Fluorescence decays of Calcium Green 1 as a function of calcium. The Calcium free form is characterised by a biexponential decay with lifetimes of 0.5 and $3.5 \mathrm{~ns}$. The contribution of the longlifetime form increases with calcium activity. Calcium activity from 0.3 to $180 \mathrm{nmol} \mathrm{L}^{-1}$. $\mathrm{pH} 7.20 ;$ EGTA + CaEGTA $=5 \mathrm{mmol} \mathrm{L}^{-1}$; TRIS $=0.1 \mathrm{~mol} \mathrm{~L}^{-1}$; excitation wavelength $=450 \mathrm{~nm}$ and emission wavelength $=530 \pm 4 \mathrm{~nm}$. (b) The family of curves has been adjusted as a linear combination of the two reference decays, Green and $\mathrm{Ca}$ Green. The differences between experimental and model data are represented for each delay of each decay curve on this $2 \mathrm{D}$ image. The larger the difference, the darker is the point. The uniform distribution of the dark points indicates a successful fit. 
52 values of calcium activity, their noise content was reduced. The reference decays, reconstructed from the main components, were averaged over the whole family of experimental data. All decays can now be decomposed as a linear combination of these two references. In Fig. 2, the ratio of their contribution is represented as a function of calcium activity. The straight line assumes a $1: 1$ stoichiometry with a $K_{\mathrm{d}}$ of 70 $\mathrm{nmol} \mathrm{L}{ }^{-1}$. From this plot, the long-lifetime component of the calcium free solution can be attributed to a Calcium Green 1 form but also to an impurity with no affinity for calcium. ${ }^{18}$ However, this invalidates the hypothesis of an impurity ${ }^{19}$ that complexs calcium with a different $K_{\mathrm{d}}$. Such an impurity could be the result of a photo-decarbonylation of the probe occurring during storage or study. ${ }^{20}$ Note the huge dynamic range allowed by time-resolved fluorescence when used with probes with a good contrast between the two free and bound forms, such as Calcium Green 1.

\section{pH dependence}

The BAPTA protonation depends on $\mathrm{pH}$ with four $\mathrm{p} K_{\mathrm{a}}$ values, the most basic being 6.4 and $5.5 .^{8}$ The fluorophore, which is a derivative of dichlorofluorescein, is also $\mathrm{pH}$ sensitive. ${ }^{21} \mathrm{We}$ recorded the fluorescence decay of Calcium Green 1 from pH 3.5 to 9 for both calcium free (Fig. 3) and calcium rich solutions (Fig. 4). For the calcium free solution, below $\mathrm{pH}$ 4 there is a change in fluorescence decay rate with $\mathrm{pH}$. Above $\mathrm{pH} 4$, the $\mathrm{pH}$ effect looks like a calcium effect. With the addition of $1 \mathrm{~mol} \mathrm{~L}^{-1} \mathrm{HCl}$ to the $0.1 \mathrm{~mol} \mathrm{~L}^{-1}$ TRIS solution, the

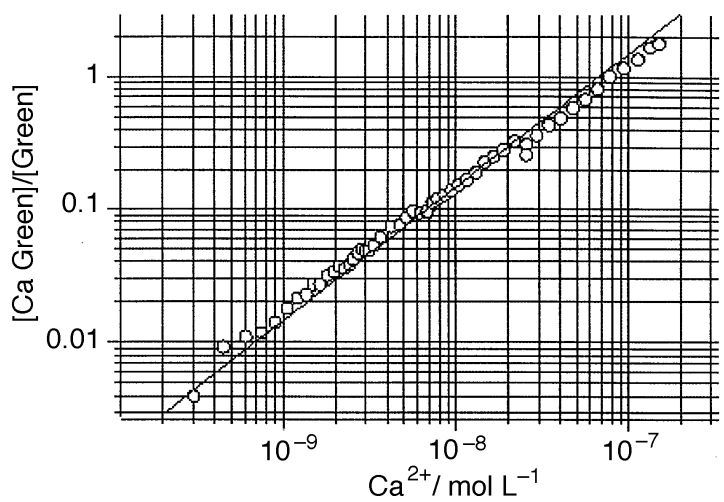

Fig. 2 The ratio of the complexed form of the probe to the free form is proportional to calcium activity over three orders of magnitude. This confirms the $1: 1$ stoichiometry of the reaction with a $K_{\mathrm{d}}$ of 70 nmol L $\mathrm{L}^{-1}$.

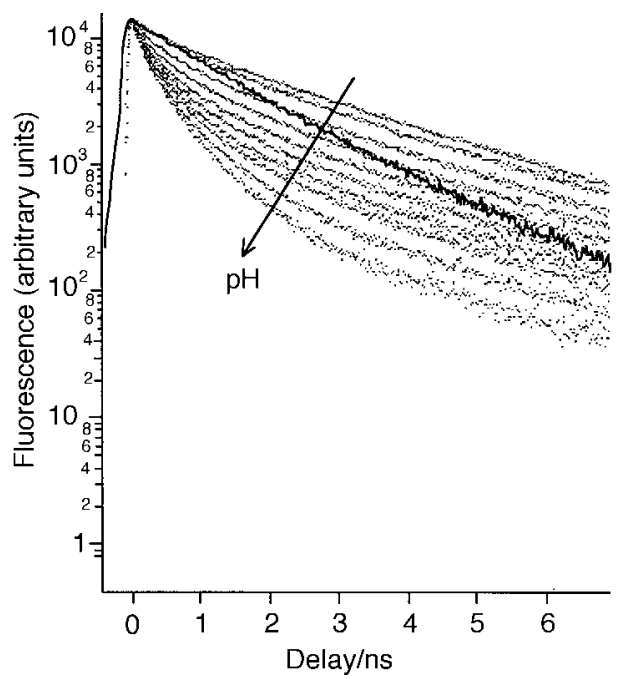

Fig. 3 Fluorescence decay of the calcium free form between $\mathrm{pH} 4$ and 9. The continuous line corresponds to $\mathrm{pH} 3.5$. The $\mathrm{pH}$ effect mimics that of calcium.

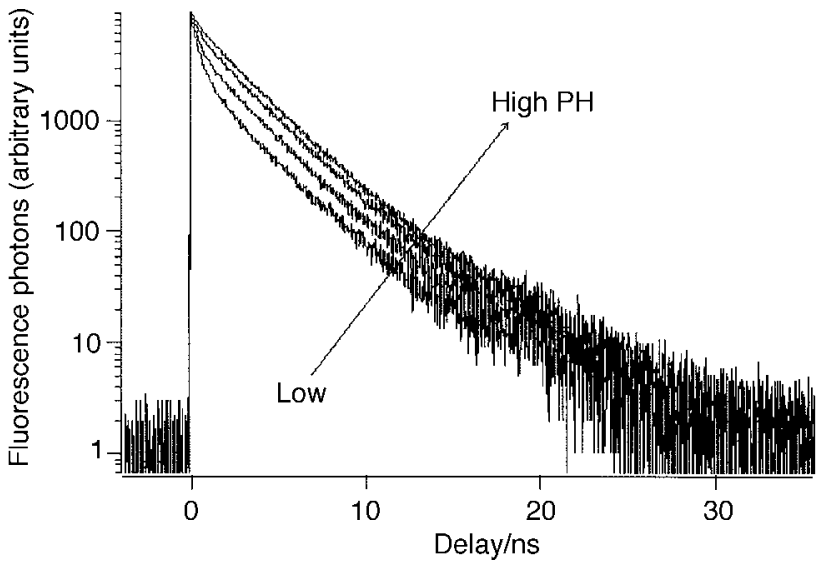

Fig. 4 Fluorescence decay of the calcium bound form of the probe between $\mathrm{pH} 4$ and 9 . Above $\mathrm{pH} 5.5$ decays do not depend on $\mathrm{pH}$.

contribution with a lifetime of 3.5 ns rises from $10 \%$ to $60 \%$. For the calcium rich solution, it can be seen that the fluorescence decay is the same at most $\mathrm{pH}$ values. Only for $\mathrm{pH}<5.5$ can a biexponential behaviour be seen, with a $\mathrm{pH}$ effect that looks like a calcium effect. We attributed this evolution to a $\mathrm{p} K_{\mathrm{a}}$ of the BAPTA moiety because it is not seen for the calcium free solution. A $\mathrm{p} K_{\mathrm{a}}$ of 4.47 was measured for the BAPTA moiety in the presence of calcium.

A main component analysis can be performed on both solutions but suggests a large number of components. We preferred to apply a simple biexponential fit that provides a phenomenological description. Lifetimes are reported in Fig. 5. The lifetime of the calcium bound form is almost independent of $\mathrm{pH}$ above $\mathrm{pH}$ 3.5. Hence, the fluorescence of the dichlorofluorescein that constitutes the fluorophore of Calcium Green 1 is not sensitive to $\mathrm{pH}^{22}$ Between $\mathrm{pH} 7$ and 9 , the short and long lifetimes of the free form are constant. From this ratio, we deduce a $\mathrm{p} K_{\mathrm{a}}$ of 6.7 for the most basic protonation of Calcium Green 1. Between $\mathrm{pH} 6.3$ and 7, the lifetimes vary, which is an indication of an excited state reactivity that involves calcium free BAPTA.

\section{Predominance domains}

From Tsien, ${ }^{8}$ we know that the dominant form of BAPTA at $\mathrm{pH} 9$ is the fully deprotonated form $\mathrm{G}^{6-}$. The $K_{\mathrm{d}}$ of Calcium Green 1 has also been measured at $\mathrm{pH} 9$ to be $70 \mathrm{nmol} \mathrm{L}^{-1}$. The $K_{\mathrm{d}}$ does not depend on $\mathrm{pH}$ between $\mathrm{pH} 7.25$ and 9 . Hence the complexation of calcium by $\mathrm{G}^{6-}$ leads to $\mathrm{CaG}^{4-}$. Three $\mathrm{p} K_{\mathrm{a}}$ values were measured as $3.5,4.47$ and 6.7 , and can be attributed to BAPTA or to the fluorophore. The protonation of BAPTA will affect the calcium complexation

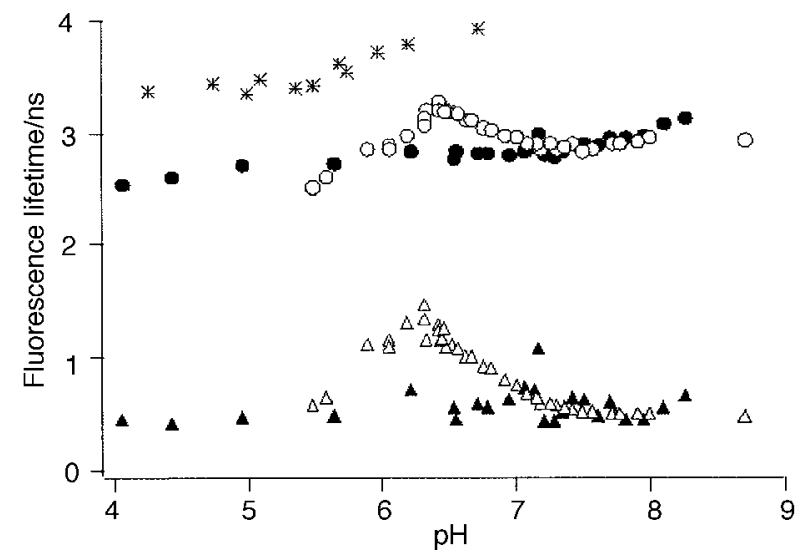

Fig. 5 Evolution of long and short fluorescence lifetimes of Calcium Green free and calcium bound form with $\mathrm{pH}$. *, Fluorescein; $\bigcirc$, long lifetime of the calcium free form;, long lifetime of the calcium complexed form; $\Delta$, short lifetime of the calcium free form; and $\boldsymbol{\Delta}$, short lifetime of the calcium complexed form. 
whereas that of the fluorophore may not. Protonation of the fluorophore will be seen for both the calcium free and the calcium rich forms. This might be the case for $\mathrm{p} K_{\mathrm{a}} 3.5$. However, the $\mathrm{p} K_{\mathrm{a}}$ values of 6.7 and 4.47 can be attributed to protonation of BAPTA, as it is not observed for both forms. The $\mathrm{p} K_{\mathrm{a}}$ value of 6.7 agrees with the reported value ${ }^{8}$ of 6.4 . From the $\mathrm{p} K_{\mathrm{a}}$ values of 6.7 and 4.47 measured for the calcium free and calcium rich form, respectively, we can deduce the following predominance domains (Fig. 6). The $K_{\mathrm{d}}$ and $\mathrm{p} K_{\mathrm{a}}$ values of Calcium Green 1 make it appropriate for applications in the physiological domain of the intracellular medium: the $K_{\mathrm{d}}$ value is close to that of intracellular calcium activity and the $\mathrm{p} K_{\mathrm{a}}$ is out of the intracellular $\mathrm{pH}$ range. However, even $0.6 \mathrm{pH}$ units away from the $\mathrm{p} K_{\mathrm{a}}$ the probe can respond to $\mathrm{pH}$ because of the very high dynamic range of calcium sensing.

\section{Dependence on sucrose}

The short-lifetime component of the fluorescence decay is attributed to quenching of the fluorochrome by an electron transfer from the BAPTA group. ${ }^{23}$ This can occur in two ways, either by dynamic quenching, with folding of the BAPTA in the excited state toward the fluorochrome, or by static quenching. This static quenching can involve transfer of the electron through the bonds or through space in a folded conformation of the molecule.

To distinguish the dynamic from the static process, the viscosity effect was checked. We measured the decay rate of the fast component in water with increasing amount of sucrose, that increases the viscosity (Fig. 7). As no dependence of the quenching rate on viscosity can be seen, quenching follows a static process.

The small dependence observed with the addition of sucrose can be explained by an electrostatic effect: the polarity of the solution changes with the addition of sucrose. As shown in Fig. 8, the logarithm of the decay rate depends linearly on $1 / \varepsilon_{\mathrm{r}}$. At the same time, the proportion of the short-lifetime contribution decreases with $1 / \varepsilon_{\mathrm{r}}$. Both effects can be explained by an electrostatic effect on a conformational equilibrium: let us call $r_{\mathrm{TT}}, r_{\mathrm{F}}$ and $r_{\mathrm{E}}$ the effective radii of the transition state and of the folded and extended form of the molecule, respectively. The electrostatic energy of these ions and their counter ion atmosphere will be

$$
w_{\mathrm{e}}=\frac{-\left|z_{+} z_{-}\right| F^{2}}{8 \pi N \varepsilon_{0} \varepsilon_{\mathrm{r}} r_{x}}
$$

where $z_{\mathrm{x}}$ is the charge of the ion and counter ions, $F$ is the Faraday constant, $N$ is Avogadro's number and $\varepsilon_{\mathrm{r}}$ is the dielectric constant of the sucrose solution. ${ }^{24}$

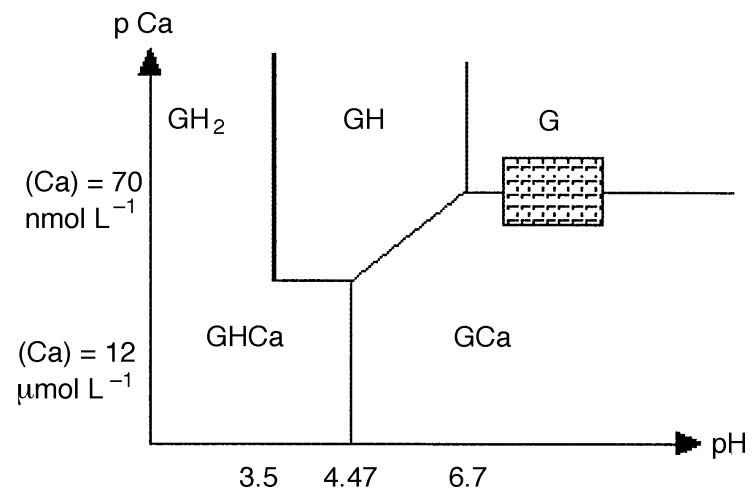

Fig. 6 Predominance domains of the different forms of Calcium Green in solution as a function of $\mathrm{pH}$ and $\mathrm{pCa}\left(=-\log \left[\mathrm{Ca}^{2+}\right]\right)$. G is the hexa-anion form, $\mathrm{GH}$ is protonated on the BAPTA group, $\mathrm{GH}_{2}$ is protonated in addition on the fluorescein, $\mathrm{GCa}$ if the tetra-anion complex of calcium and GHCa is protonated on the BAPTA group. The box indicates the region of interest for intracellular measurements.

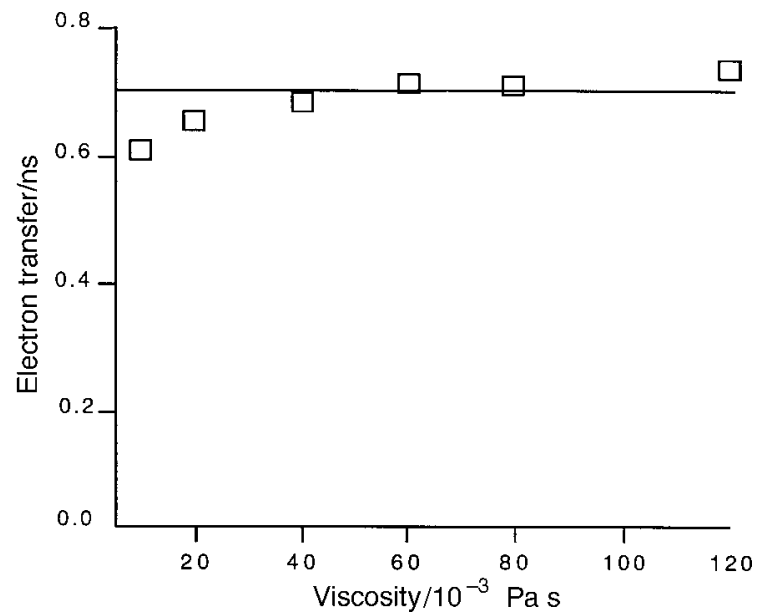

Fig. 7 Evolution of the short-lifetime form as a function of added sucrose. The electron transfer rate is independent of viscosity. The quenching does not proceed through the folding of the molecule in the excited state.

The position of the equilibrium between two charged conformers will depend on their size and on solvent polarity according to

$$
\begin{aligned}
R T \ln \left(K_{\mathrm{F} / \mathrm{E}}\right) & =R T \ln \left(K_{0}\right)+\Delta w_{\mathrm{e}} \\
& =R T \ln \left(K_{0}\right)+\frac{C}{\varepsilon}\left(\frac{1}{r_{\mathrm{F}}}-\frac{1}{r_{\mathrm{E}}}\right)
\end{aligned}
$$

where

$$
C=\frac{-\left|z_{+} z_{-}\right| F^{2}}{8 \pi N}
$$

As observed, the folded conformation is favoured in a high polarity medium.

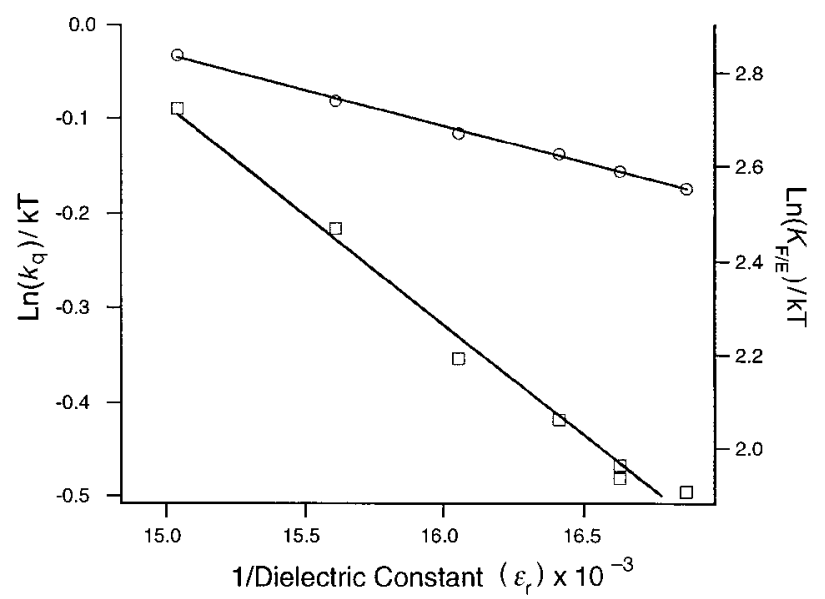

Fig. 8 Conformational equilibrium $K_{\mathrm{F} / \mathrm{E}}(\square)$ and decay rate $k_{\mathrm{q}}(\mathrm{O})$ of the short-lifetime component as a function of the relative dielectric constant. The energy $w_{\mathrm{e}}$ of a charged molecule of radius $r_{\mathrm{x}}$ is affected by polarity $\varepsilon_{\mathrm{r}}$ according to $w_{\mathrm{e}}=\left(-\left|z_{+} z_{-}\right| F^{2}\right) /\left(8 \pi N \varepsilon_{0} \varepsilon_{\mathrm{r}} r_{x}\right)$. In Calcium Green 1, it affects the conformational equilibrium, the smaller conformers being disfavoured in non-polar environments. The proportion of the folded conformer is decreased $\left(K_{\mathrm{F} / \mathrm{E}}\right.$ from 95 to $85 \%$ ) on adding sucrose. The quenching time is also increased from 0.65 to $0.8 \mathrm{~ns}$ since the transition state is small and disfavoured when sucrose is added. From the slopes one can estimate radii of $0.27,0.3$ and $0.47 \mathrm{~nm}$ for the transition state, the folded conformer and the extended conformer, respectively. 
The reaction rate can be expressed as

$$
\ln k_{\mathrm{q}}=\ln \left(k_{q_{0}}\right)+\frac{C}{R T \varepsilon}\left(\frac{1}{r_{\mathrm{TT}}}-\frac{1}{r_{\mathrm{F}}}\right)
$$

The reaction rate increases in a high polarity medium as observed. From the slopes and assuming a radius of $0.3 \mathrm{~nm}$ for the folded conformer, one can estimate the radii of the three conformations: $r_{\mathrm{TT}}=0.27, r_{\mathrm{F}}=0.30$ and $r_{\mathrm{E}}=0.48 \mathrm{~nm}$.

The independence of the quenching rate of the viscosity confirms that quenching proceeds through a static electron transfer. From the point of view of applications, Calcium Green is not sensitive to local viscosity. Both the dependence of the long-lifetime component on polarity and that of quenching rate confirm that the Calcium Green fluorescence is controlled by a conformational equilibrium.

\section{Adsorption on proteins}

Adsorption on proteins ${ }^{25,26}$ and interaction with histidine ${ }^{27}$ groups of the protein have been observed for BAPTAcontaining probes. Adsorption can be checked with bovine serum albumin (BSA) using fluorescence anisotropy. Fluorescence anisotropy allows the measurement of the hydrodynamic volume $V$ of the fluorescent molecule according to ${ }^{28}$

$$
1 / \tau_{\mathrm{D}}=k T / \eta V
$$

where $\tau_{\mathrm{D}}$ is the rotational diffusion time, $\eta$ is the solvent viscosity, $k$ is the Bolzmann constant and $T$ is the absolute temperature.

We measured the fluorescence anisotropy of Calcium Green 1 as 0.17 in water and it reached the maximum value of 0.35 in the presence of BSA. Fig. 9 shows that Calcium Green molecules are adsorbed at less that $30 \mathrm{~g} \mathrm{~L}^{-1}$ of BSA.

Adsorption on the BSA also influences fluorescence decay. The fluorescence decay rates are not significantly changed by the adsorption but the proportion of the long-lifetime component is increased. Such a change can be explained either by the complexation of histidine, which would mimic that of calcium, or it can be an effect of adsorption that changes the ground state conformational equilibrium and favours the unfolded conformation of the molecule.

\section{Anisotropy in cells}

Anisotropy was measured in RINm5F cells (Fig. 10) that had been permeabilized with ionomycin and placed in a calcium buffer to fix the intracellular calcium activity. No specific organelles were targetted. Only a local maximum was chosen for measurement. The short-lifetime component of the anisotropy relaxation was calculated. The same rotational relaxation time $\tau_{\mathrm{D}}$ was measured in all cases with a value of $1.33 \pm 0.11 \mathrm{~ns}$ (standard deviation of the mean, $n=10$ ) corresponding to a Calcium Green molecule that rotates in a

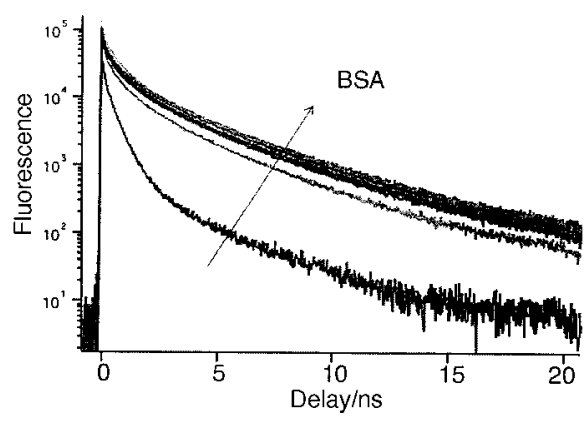

Fig. 9 Adsorption of Calcium Green 1 on albumin modifies the conformational equilibrium. Adsorption is confirmed by anisotropy measurements. $\mathrm{pH} 7.2 ; \mathrm{KCl}=1 \mathrm{~mol} \mathrm{~L}{ }^{-1} ; \mathrm{EGTA}=10 \mathrm{mmol} \mathrm{L}^{-1}$; albumin $=20-80 \mathrm{~g} \mathrm{~L}^{-1}$.

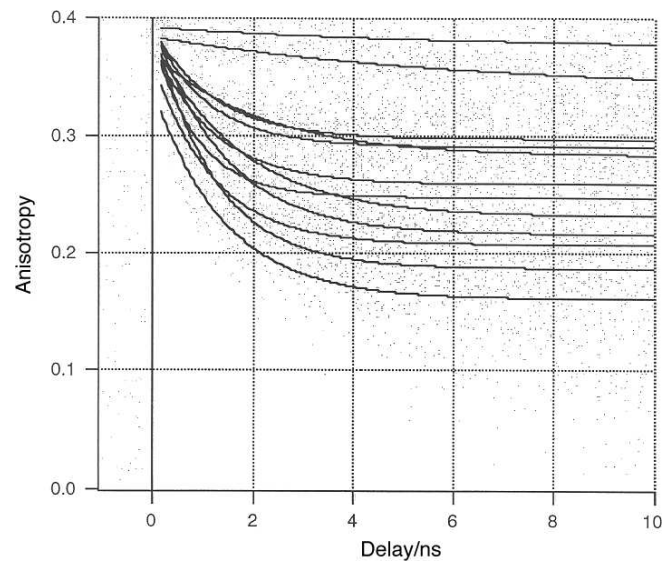

Fig. 10 The relaxation of fluorescence anisotropy was measured in 12 individual RINm5F cells incubated in RPMI medium. Part of the anisotropy relaxes within $2 \mathrm{~ns}$, corresponding to a free probe. The remaining anisotropy relaxes over a very long time corresponding to probes adsorbed on proteins. The proportions of the two components vary strongly from cell to cell.

medium with a viscosity of $3.2 \pm 0.3 \mathrm{cP}$. That is three times the viscosity of water.

The amplitude of the anisotropy relaxation varied from one sample to another. It was always positive and less than 0.4. The presence of long-lasting anisotropy is due to adsorption of the probe on the protein. The dispersion of the extent of the adsorption is probably due to the fact that we were not always looking at the same subcellular organelles.

\section{Hydrolysis of the cell permeant form}

Calcium Green 1 is a highly polar molecule, which prevents the probe from penetrating through the cell membranes. The acetoxymethyl esters of Calcium Green 1 (GreenAM) are a neutral form of the molecule that can penetrate into the cells. ${ }^{29}$ In situ hydrolysis is done by cytosolic esterase. We followed the fluorescence intensity and fluorescence decay during the hydrolysis of GreenAM. The hydrolysis was performed using 0.04 unit of esterase from Mucor miehei (triacylglycerol acyl-hydrolase) in $10 \mathrm{ml}$ of water at $\mathrm{pH} 7.2$ in the absence of any calcium chelator. As shown in Fig. 11, the total intensity rises quickly to a quarter of the maximum value in the first few seconds. This rapid rise is due to opening of the lactone function that releases the aromaticity of the fluorescein ring. The associated fluorescence decay is biexponential

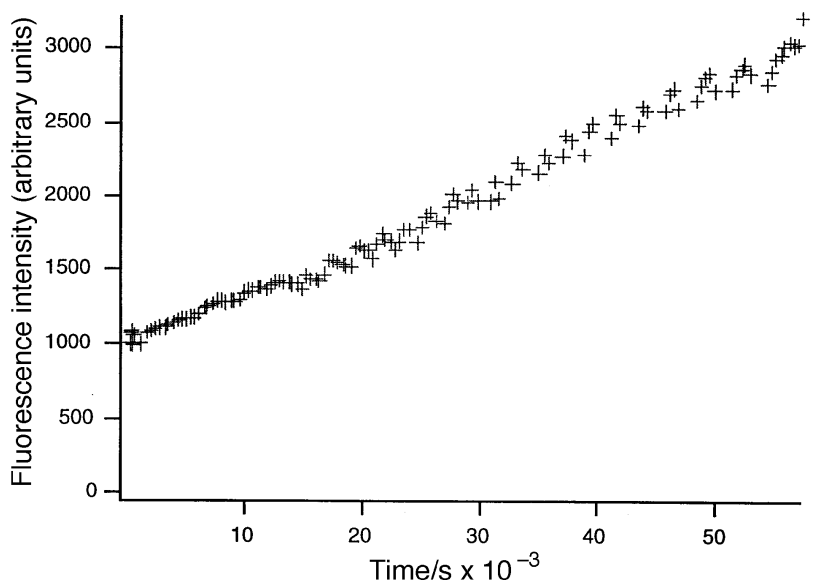

Fig. 11 Development of the fluorescence intensity during hydrolysis of the acetoxymethyl esters of Calcium Green 1 by 0.04 unit of Mucor miehei triacylglycerol acyl-hydrolase in $10 \mathrm{ml}$ of water at $\mathrm{pH}$ 7.2. The initial prompt increase is due to the opening of the lactone function of fluorescein. 
with a short lifetime of $1 \mathrm{~ns}$ characteristic of a folded conformation. The slow increase of the fluorescence intensity that is observed later is associated with the appearance of a longlifetime component characteristic of the calcium bound form. Six ester functions are present in GreenAM. Hence $2^{6}=64$ intermediates can be produced before complete hydrolysis. A chemometric analysis of the family of fluorescence decays showed that at least four fluorescence profiles can be distinguished during the hydrolysis. This large number of components prevents the correction of calcium activity measurements for partial hydrolysis.

\section{Discussion}

\section{The long-lifetime component of the Calcium Green fluorescence}

The decay of the calcium free form of Calcium Green presents a long-lifetime component that should be discussed, ${ }^{30}$ even if the amount of impurity is $3 \%$. The presence of an impurity was suggested with the first samples. ${ }^{31}$ Scheenen et al. ${ }^{20}$ showed that fluorescent photo-products are produced during fluorescence studies. This should be a minor contribution in our results, which were mainly obtained using a large volume cuvette in which the sample was continuously stirred. The linear relationship that we observed between calcium activity and the evolution of the fluorescence decay is not proof of purity. This relationship represents the evolution of the fluorescence signal and an impurity whose fluorescence is independent of calcium activity will not influence that evolution. On the other hand, the fluorescence of impurities such as the photodegradation products that still contain some part of the BAPTA group depends on calcium activity. The linear plot in Fig. 2 confirms the absence of such an impurity. In cells, we have seen that Calcium Green is subjected to the same photodestruction that leads to an under-estimation of the calcium activity. ${ }^{32}$ The influence of the polarity on the amplitude of the long-lifetime component is direct evidence for the absence of an impurity of any type. The presence of an impurity at more than $2 \%$ would have distorted the correlation.

\section{Electron transfer process}

The fluorescence of Calcium Green is independent of viscosity, hence the quenching process is not due to the folding of the molecule in the excited state. The effect of polarity on the quenching rate confirms that the quenching proceeded through a movement of charges. However, the quenching rate cannot distinguish between a through-bond electron transfer and an electron transfer in a folded transition state. The effect of protein adsorption and of polarity on the amplitude of the long-lifetime component cannot be explained by a throughbond electron transfer, as this transfer should occur whatever the conformation of the molecule. The existence of quenched and non-quenched conformations favours through-space electron transfer in a folded transition state.

Hence the fluorescence reflects a ground state conformational equilibrium. Such a ground state equilibrium might be seen in absorption or excitation spectra by the presence of a charge transfer band. Such a strong interaction in the ground state is not seen and such a conformer would be nonfluorescent or show a very fast decay of fluorescence. However, the absence of such a strong interaction does not preclude the existence of slowly interconverting conformers.

\section{Calcium Green 1 as a probe}

The influence of adsorption on the probe response is due to the probe mechanism that occurs through a ground state conformation equilibrium. This type of probe mechanism gives a signal that is relatively insensitive to the origin of the perturbation. That is why calcium complexation, protonation, partial hydrolysis and adsorption will all modify the ratio of the two components of the fluorescence without changing their lifetime. The through-bond electron transfer mechanism that was proposed originally would have provided a probe with a much richer response and open the way to an absolute measurement of calcium activity in living cells.

As a probe, Calcium Green behaves satisfactorily. The response is independent of viscosity and it is only slightly dependent on polarity. Even though the $\mathrm{p} K_{\mathrm{a}}$ of 6.7 of the BAPTA group falls outside the physiological domain, $\mathrm{pH}$ may interfere during the measurement of very low calcium activity. The major concern is adsorption on proteins, the variability of which will disturb quantitative measurements in cells but will not disturb relative measurements. We have used Calcium Green 1 for ex vivo studies. Hydrolysis occurs within $30 \mathrm{~min}$. Photo-destruction of the BAPTA moiety can be rendered negligible by reducing the light intensity. ${ }^{14}$

\section{Conclusions}

Calcium Green 1 allows the measurement of calcium activity in fluorescence lifetime studies over three orders of magnitude, between $0.3 \mathrm{nmol} \mathrm{L}^{-1}$ and $0.2 \mu \mathrm{mol} \mathrm{L}{ }^{-1}$, with a $K_{\mathrm{d}}$ of 70 $\mathrm{nmol} \mathrm{L} \mathrm{L}^{-1}$. The probe is also sensitive to $\mathrm{pH}$ with a $\mathrm{p} K_{\mathrm{a}}$ of 6.7. It is not sensitive to viscosity and only slightly to polarity. From the study of the polarity effect, we propose that the Calcium Green response is due to a ground state conformation at equilibrium. This agrees with the influence of the adsorption of the probe on its fluorescence decay profile. The short lifetime of the calcium free form of Calcium Green is due to a through-space electron transfer occurring in a folded conformation.

\section{Acknowledgements}

We thank J. Souppe of Gist Brocades for the gift of Mucor miehei esterase and Danielle Pansu and Christine Bernard of INSERM, U45, for growing the cell cultures.

\section{References}

1 K. Calsson, P. E. Danielsson, R. Lenz, A. Liljeborg, L. Majlof and N. Aslund, Opt. Lett., 1985, 10, 53; W. Denk, J. H. Strickler and W. W. Webb, Science, 1990, 248, 73; W. Denk, Photonics Spectra, 1997, 125

2 H. Szmacinski and J. R. Lakowicz, in Topics in Fluorescence Spectroscopy, ed. J. R. Lakowicz, Plenum Press, New York, 1994, vol. 4, p. 295.

3 R. A. Bissel, A. P. de Silva, H. Q. N. Gunarantne, P. L. M. Lynch, G. E. M. Maguire and K. R. A. S. Sandanayake, Chem. Soc. Rev. 1992, 21, 187; R. A. Bissel, A. P. de Silva, H. Q. N. Gunarantne, P. L. M. Lynch, G. E. M. Maguire, C. P. McCoy and K. R. A. S. Sandanayake, Top. Curr. Chem., 1993, 166, 223; P. A. De Silva N. Gunaratne, T. Gunnlaugsson, A. J. M. Huxley, C. P. McCoy, J. T. Rademacher and T. E. Rice, Chem. Rev., 1997, 97, 1515

4 A. P. de Silva and K. R. A. Sandanayake, Tetrahedron Lett, 1991, 32, 421; A. P. de Silva and S. A. de Silva, J. Chem. Soc. Chem. Commun., 1986, 1709

5 W. N. Ross, Biophys. J., 1993, 64, 1655.

6 J.-M. Millot, L. Pingret, J.-F. Angiboust, A. Bonhomme, J.-M. Pinon and M. Manfait, Cell Calcium, 1995, 17, 354

7 M. Poenie, Cell Calcium, 1990, 11, 85

8 R. Y. Tsien, Biochemistry, 1980, 19, 2396.

9 M. A. Kuhn, in Fluorescent Chemosensors for Ion and Molecule Recognition, ed. A. W. Czarnik, American Chemical Society, Washington, DC, 1993, p. 147.

10 A. P. de Silva, H. Q. Nimal Gunaratne and G. E. M. Maguire, J Chem. Soc., Chem. Commun., 1994, 1213.

11 A. P. de Silva and H. Q. Nimal Gunaratne, J. Chem. Soc., Chem. Commun., 1990, 186.

12 T. Araki and M.-O. Yamada, Acta Histochem. Cytochem., 1986, 19, 83 .

13 K. P. Ghiggino, P. G. Spizzini and T. A. Smith, in Spectroscopy and chemistry in small domains, ed. H. Masuhara, Elsevier, Amsterdam, 1994

14 L. Schoutteten, P. Denjean and R. B. Pansu, J. Fluorescence, 1997, 7, 155 . 
15 A. F. Gazdar, W. L. Chick, H. Oie, H. L. Sims, D. L. King, G. C. Weir and V. Lauris, Proc. Natl. Acad. Sci. USA, 1980, 77, 3519.

16 M. Kubista, R. Sjöback and J. Nygren, Anal. Chim. Acta, 1995, 302, 121; M. Kubista, R. Sjöback and B. Albisson, Anal. Chem., 1993, 65, 994; Chemometrics Tool Box, MathWorks, Natick, MA 1992.

17 S. Kawata, H. Komeda, K. Sasaki and S. Minami, Appl. Spectrosc., 1985, 39, 610.

18 R. B. Pansu and K. Yoshihara, J. Phys. Chem., 1991, 95, 10123.

19 M. Eberhard and P. Erne, Biochem. Biophys. Res. Commun., 1991, 180, 209.

20 W. J. Scheenen, L. R. Makings, L. R. Gross, T. Pozzan and R. Y. Tsien, Chem. Biol., 1996, 3, 765.

21 C. G. Knight and A. Matthews, Biochim. Biophys. Acta, 1989, 985, 75 .

22 M. M. Martin and L. Lindqvist, J. Lumin., 1975, 10, 381.

23 M. A. Kuhn, in Fluorescent Chemosensors for Ion and Molecule Recognition, ed. A. W. Czarnik, American Chemical Society, Washington, DC, 1993, p. 147.
24 W. M. Arnold, A. G. Gessner and U. Zimmermann, Biochem. Biophys. A, 1993, 1157, 32.

25 W. N. Ross, Biophys. J., 1993, 64, 1655.

26 F. Bancel, J. Salmon, J. Vigo, T. Vo-Dinh and P. Viallet, Anal. Biochem., 1992, 204, 231.

27 J. Chahboun, J.-M. Salmon and P. J. Viallet, Photochem. Photobiol. B, 1996, 33, 125.

28 C. R. Cantor and P. R. Schimmel. Fluorescence Spectroscopy, Biophysical Chemistry, Part II, Freeman, San Francisco, 1980, p. 432.

29 K. M. Wright and K. J. Oparka, J. Exp. Bot., 1996, 47, 304, 1779.

30 R. Sanders, H. C. Gerristen, A. Draaijer, M. P. Houpt and Y. K. Levine, Bioimaging, 1994, 2, 131.

31 M. Eberhard and P. Erne, Biochem. Biophys. Res. Commun., 1991, 180, 209.

32 L. Schoutteten, P. Denjean, G. Joliff-Botrel, C. Bernard, D. Pansu and R. B. Pansu, Photochem. Photobiol., submitted for publication.

Paper 9/00584F 